\section{Removal technique for grapefruit-sized BioEnterics intragastric balloon}

Gastric balloons were quickly adopted as a method of treating obesity. The most widely used system features a saline-filled silicone balloon [1-2]. However, gastroenterologists are sometimes unfamiliar with methods of removing these endoscopically placed gastric balloons [3].

A 45-year-old woman presented with nausea and coffee-ground vomiting that had persisted for 5 days before admission. She had had a gastric balloon placed 16 days earlier. The physical examination revealed abdominal distension and tenderness, without rebound. Abdominal computed tomography showed no free intraperitoneal air and the presence of a gastric balloon in the body of the stomach, with fluid above the balloon.

At endoscopy, it was found that the gastric balloon had become impacted in the antrum (Figure 1). A rat-toothed biopsy forceps was used to puncture the outer skin of the balloon, and 11 of blue dye solution was removed. A polypectomy snare was used to try to ensnare the balloon. However, the diameter of the snare was too small, and extraction of the balloon using rat-toothed forceps also failed.

A home-made snare was then devised that was large enough to surround a section of the balloon and allow it to be withdrawn. The snare was created by folding in half a 0.035 -inch endoscopic retrograde cholangiopancreatography (ERCP) guide wire. The ends of the wire were threaded through the plastic sheath of an injector needle, with the loose ends of the wire being held in place with an alligator clamp. The wire loop was withdrawn into the sheath, and the sheath was passed blindly into the stomach, like an orogastric tube. A rat-toothed forceps was then

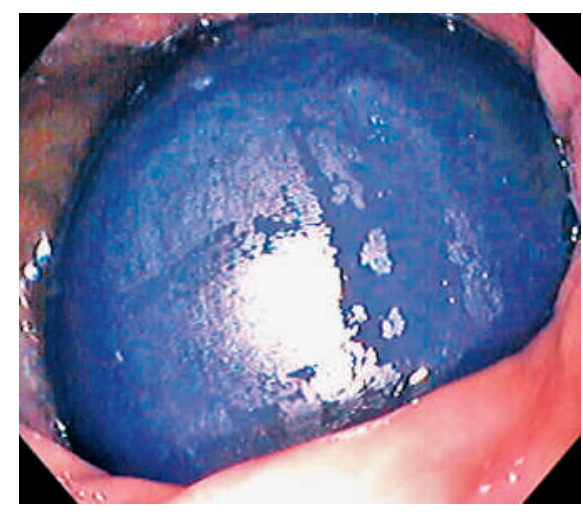

Figure 1 The impacted gastric balloon in the antrum.

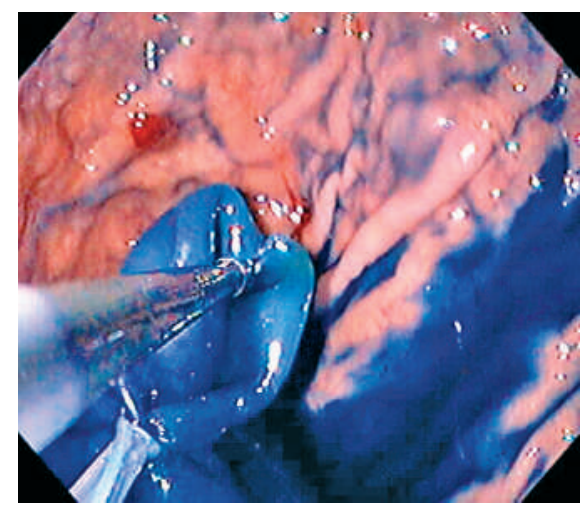

Figure 2 The biopsy forceps being used to position the balloon so that the snare (lower left) can surround and grasp it.

passed through the biopsy channel of an Olympus GIF-140 endoscope and advanced through the partially opened snare. The forceps was used to grasp the balloon and withdraw a section of it measuring approximately $4 \times 3 \mathrm{~cm}$ into the open snare. The snare was then closed, grasping the balloon (Figure 2 ).

\section{Competing interests: None}

Endoscopy_UCTN_Code_TTT_1AO_2AL
J. O. Gonzalez' , J. S. Barkin ${ }^{2}$

${ }^{1}$ Miller School of Medicine, University of Miami, Miami, Florida, USA

2 Division of Gastroenterology, Mount Sinai Medical Center, Miami, Florida, USA.

\section{References}

${ }^{1}$ Durrans D, Taylor TV, Pullan BR, Rose P. Intragastric balloons: short term solution to a long term problem? J R Coll Surg Edinb 1985; 30: 369-371

2 Mathus-Vliegen EMH. Efficacy of the BioEnterics intragastric balloon treatment in a prospective 2 year follow-up study. Paper presented at the 8th European Congress on Obesity, Trinity College, Dublin: 18-21 June 1997

${ }^{3}$ Mirich DR, Gray RR, Haber GB. Percutaneous deflation of a gastric balloon: technical note. Cardiovasc Intervent Radiol 1989; 12: 164 165

\section{Corresponding Author}

\section{J. S. Barkin, M.D.}

Division of Gastroenterology

Mount Sinai Medical Center

4300 Alton Road

Miami Beach, Florida 33140

USA

Fax: $\quad+1-305-674-2671$

E-mail: jamiebarkin@msmc.com 